\title{
DESENVOLVIMENTO LARVAL DE ERIPHIA GONAGRA (FABRICIIUS, 1781) (DECAPODA, XANTHIDAE), EM LABORATÓRIO
}

\author{
Adilson Fransozo'
}

\begin{abstract}
The post-embryonic development of the crab from the north coast of São Paulo State, Eriphia gonagra (Fabricius) was studied in laboratory. The experiments were performed in a climatically controlled room at $24 \pm 1{ }^{\circ} \mathrm{C}$ at a salinity of $36^{\circ} \%$ and the animals were fed with newly hatched Artemia salina nauplii.

The larval development of E. gonagra comprises 4 stages of zoea and one megalopa. All larval stages are illustrated and described in detail.

The main morphological characters that allow the identification of the zoeae and megalopae of $\mathrm{E}$. gonagra are analyzed with respect to other Brasilian species of the family Xanthidae.
\end{abstract}

\section{INTRODUÇÃO}

De acordo com Costlow \& Bookhout (1967), os primeiros estudos sobre as formas larvais dos Brachyura pertencentes à familia Xanthidae tiveram início com o trabalho de Birge, em 1883, onde são descritos os estágios de Neopanope texana sayi (Smith), provenientes de material planctônico.

No Brasil, esta família é representada por trinta e sete espécies, das quais apenas Panopeus herbstii Milne-Edwards, Pilumnus dasypodus Kingsley e Menippe nodifrons Stimpson, foram estudadas quanto ao desenvolvimento pós-embrionário por, respectivamente, Costlow \& Bookhout (1961), Sandifer (1974) e Scotto (1979). Mais recentemente, Negreiros-Fransozo (1984), estudou outras duas espécies: Panopeus americanus Saussure e Eurypanopeus abbreviatus (Stimpson).

Com relação específica ao gênero Eriphia Latreille, os primeiros estudos sobre suas formas larvais foram realizados por Hyman (1925) que,

1. Departamento de Zoologia - Instituto Básico de Biologia Médica e Agricola - Campus de Botucatu - UNESP - Caixa Postal 502 - CEP 18610 - Botucatu - SP. 
através de coletas de material planctônico, identificou algumas zoeas de E. spinifrons (Herbst). Posteriormente, o único trabalho sobre metamorfose, neste gênero, foi efetuado por Lumare \& Gozzo (1972), com a descrição de todos os estágios de $E$. verrucosa (Forskal), uma espécie pertencente ao hemisfério norte.

O presente trabalho tem por objetivo principal apresentar as descrições morfológicas dos estágios larvais envolvidos no desenvolvimento de E. gonagra. Paralelamente, será apresentado um estudo comparativo com as outras espécies de Xanthidae, pertencentes à fauna carcinológica brasileira.

\section{MATERIAL E MÉTODOS}

As coletas de Eriphia gonagra (Fabricius, 1781), foram realizadas no litoral norte do Estado de São Paulo, nas praias dos municípios de São Sebastião $\left(23^{\circ} 49^{\prime} \mathrm{S}\right.$ e $\left.45^{\circ} 24^{\prime} \mathrm{W}\right)$ e Ubatuba $\left(23^{\circ} 26^{\prime} \mathrm{S}\right.$ e $\left.45^{\circ} 05^{\prime} \mathrm{W}\right)$ onde, por ocasião da maré baixa, os animais são vistos entre as rochas ou aglomerados de Polychaeta do gênero Phragmatopoma.

As larvas recém-eclodidas (zoeas I) foram isoladas em placas de $\mathrm{Pe}$ tri de $20 \mathrm{ml}$ e, em grupos de 10 , em placas de $80 \mathrm{ml}$.

Os trabalhos em laboratórios foram efetuados em uma sala climática com temperatura de $24 \pm 1^{\circ} \mathrm{C}$, utilizando-se como alimento para as larvas náuplios recém-eclodidos de Artemia salina, introduzidos diariamente após a troca de água.

tura de ălcool etílico $96 \%$ e glicerina na proporção de 1:1 e as exúvias em glicerina. Os desenhos e medidas foram realizados com auxilio de microscópio provido de câmara clara, utilizando-se em média 10 larvas de cada estágio.

\section{RESULTADOS}

Com as coletas periódicas, constatou-se que as fêmeas ovigeras de E. gonagra ocorrem o ano todo, com maior incidência nos meses mais quentes, entre novembro e março.

Os melhores resultados para obtenção e criação de larvas em laboratório foram conseguidos a partir de fêmeas com ovos em estágios finais do desenvolvimento embrionário, caracterizados por apresentarem embriões com olhos compostos facilmente observáveis através da membrana envoltória do ovo.

E. gonagra apresenta o desenvolvimento pós-embrionário constituído por 4 estágios de zoea e um de megalopa.

Nos experimentos com larvas isoladas, os melhores resultados foram obtidos na salinidade $36 \%$. 


\section{Zoea I}

(Fig. 1-I a 10-I)

A carapaça (Fig. 1-I) apresenta 2 pequenos espinhos laterais, 1 longo espinho dorsal e 1 espinho rostral que ultrapassa as projeçōes antenais. Olhos sésseis. Abdome (Fig. 2-I) constituído por 5 segmentos cilíndricos, desprovidos de apêndices. Sexto segmento abdominal fundido ao telso. O segundo segmento abdominal apresenta um par de nódulos laterais e o terceiro um par de espinhos. Telso (Fig. 3-I) bifurcado, apresentando, em cada ramo, 2 espinhos laterais e 1 dorsal. Em sua margem interna, o telso sustenta 6 cerdas plumosas, dispostas simetricamente 3 a 3 , de cada lado do entalhe mediano.

Antênula (Fig. 4-I) - unirreme, ligeiramente cônica, com 2 estetos longos e 1 curto, na região distal.

Antena (Fig. 5-I) - protopodito afilado, com duas fileiras de pequenos espinhos na metade distal. Exopodito com o comprimento equivalente a $3 / 4$ do protopodito, provido de 3 cerdas simples distais, de diferentes tamanhos.

Mandíbula (Fig. 6-I) - processo incisivo com 3 proeminências dentiformes e processo molar com a margem interna provida de 3 pequenos dentes.

Maxílula (Fig. 7-I) - endopodito bisegmentado, com 1 cerda plumosa no segmento proximal e 6 no distal. Protopodito apresenta o endito basal com 5 cerdas plumosas e o endito coxal com 6 .

Maxila (Fig. 8-I) - endopodito não segmentado, com 5 cerdas plumosas terminais e 3 subterminais. Protopodito subdividido em endito basal e endito coxal, ambos bilobados (lobos distal e proximal). Endito basal com 4 cerdas plumosas em cada lobo. Endito coxal com 3 cerdas plumosas no lobo distal e 5 no proximal. Exopodito (escafognatito) com 4 cerdas plumosas e um prolongamento afilado, com duas fileiras de pequenas cerdas simples.

Primeiro Maxilipede (Fig. 9-I) - coxopodito liso e basipodito com 10 cerdas plumosas na sua margem interna. Endopodito pentasegmentado com 2, 2, 1, 2 e 5 cerdas plumosas do segmento proximal para o distal. Exopodito bisegmentado, com 4 longas cerdas natatórias no segmento distal.

Segundo Maxilipede (Fig. 10-I) - coxopodito liso e basipodito com 4 cerdas plumosas na sua margem interna. Endopodito trisegmentado com 1,1 e 6 cerdas plumosas do segmento proximal para o distal. Exopodito bisegmentado, com 4 longas cerdas plumosas natatórias no segmento distal. 


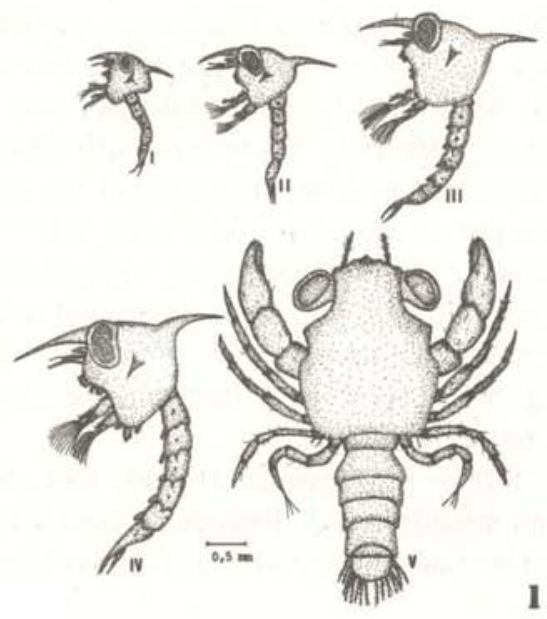

Fig. 1: Eriphia gonagra (Fabricius, 1781). Vista latera., i, II, III e IV, estágios de zoea. Vista dorsal V, megalopa.

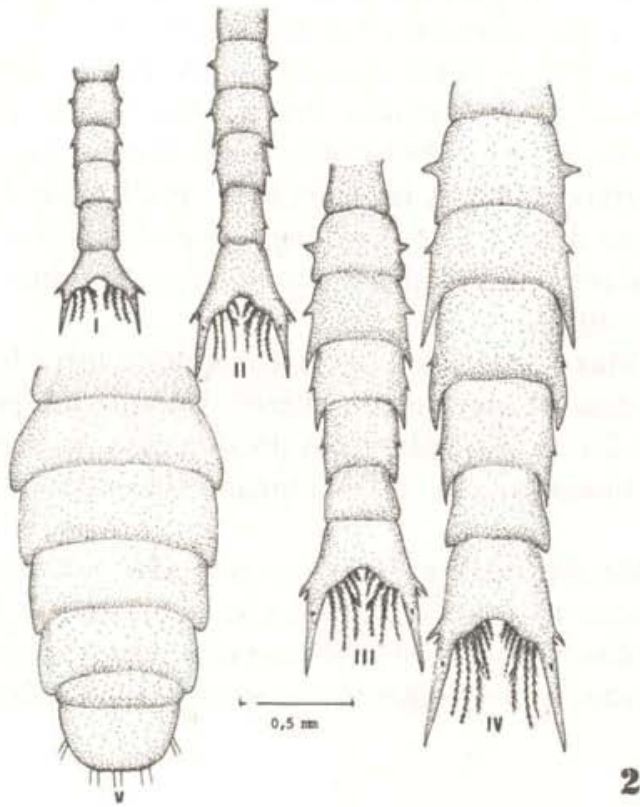

Fig. 2: Eriphia gonagra (Fabricius, 1781). Vista dorsal do abdome, I, II, III e IV, estágios de zoea e V, megalopa. 


\section{Zoea II}

\section{(Figuras 1-II a 10-II)}

A forma geral do corpo (Fig. 1-II) é semelhante à da zoea I, porém de maior tamanho. Olhos ligeiramente pedunculados. O abdome (Fig. 2II) apresenta um par de nódulos laterais no segundo segmento e um par de espinhos póstero-laterais no terceiro e quarto. O terceiro, quarto e quinto segmentos apresentam, ainda, um par de espinhos menores, em posição látero-mediana. O telso (Fig. 3-II) apresenta 8 cerdas plumosas, em sua margem interna, dispostas simetricamente 4 a 4 .

Antênula (Fig. 4-II) - protopodito com 6 estetos de diferentes tamanhos, em sua região distal.

Antena (Fig, 5-II) - protopodito e exopodito semelhantes ao da zoea I. Endopodito rudimentar, fundido ao protopodito.

Mandibula (Fig. 6-II) - bastante semelhante à da zoea I, nas com os dentes de maior tamanho.

Maxilula (Fig. 7-II) - endopodito sem modificações, quanto ao número de cerdas. Endito basal com 9 cerdas plumosas e endito coxal com 7. Protopodito com 1 cerda plumosa na margem interna.

Maxila (Fig. 8-II) - endopodito semelhante ao da zoea I. Endito basal com 5 cerdas plumosas no lobo distal e 4 no proximal. Endito coxal com 4 cerdas plumosas no lobo distal e 6 no proximal. Exopodito com 14 cerdas plumosas marginais.

Primeiro Maxilipede (Fig. 9-II) - basipodito e endopodito sem modificações quanto ao número de cerdas. Exopodito com 6 longas cerdas plumosas, no segmento distal.

Segundo Maxilipede (Fig. 10-II) - basipodito e endopodito semelhantes ao da zoea I. Exopodito com 6 longas cerdas plumosas no segmento distal.

\section{Zoea III}

(Fig. 1-III a 10-III)

A carapaça (Fig. 1-III) é maior que a da zoea II, apresentando o mesmo número de espinhos. Olhos ligeiramente pedunculados. $\mathrm{O}$ abdome (Fig. 2-III) apresenta o sexto segmento separado do telso e um par de espinhos póstero-laterais no quinto. Do segundo ao quinto segmentos surgem os rudimentos dos pleópodos. Telso (Fig. 3-III) apresenta, na sua superfície interna, 10 cerdas plumosas dispostas simetricamente 5 a 5 .

Antênula (Fig. 4-III) - protopodito com 9 estetos distais. Em sua região mediana surge o rudimento do endopodito.

Antena (Fig. 5-III) - protopodito e expodito semelhantes ao estágio anterior. Endopodito com aproximadamente a metade do comprimento do exopodito. 


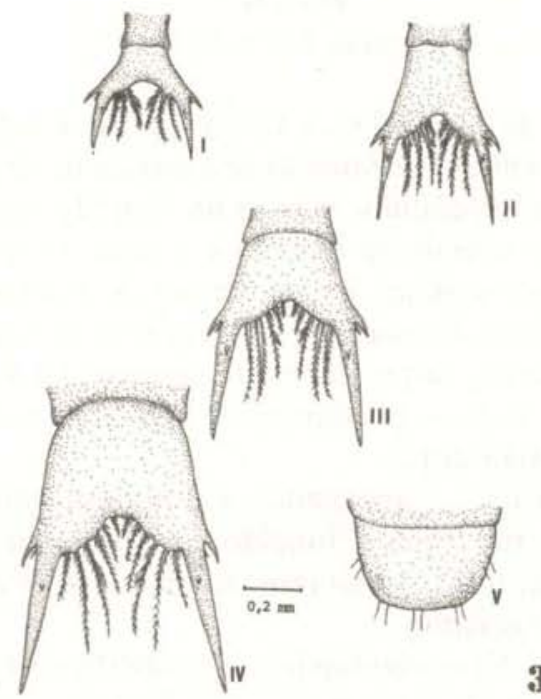

Fig. 3: Eriphia gonagra (Fabricius, 1781). Vista dorsal do telso, I, II, III e IV estágios de zoea e V, megalopa.
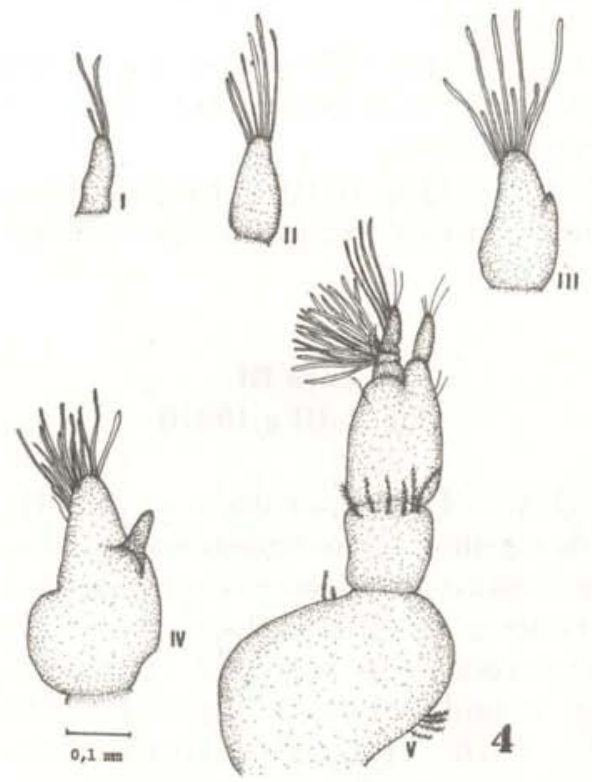
Fig. 4: Eriphia gonagra (Fabricius, 1781). Antênula, I, II, III e IV. estágios de zoea e V,
megalopa. 

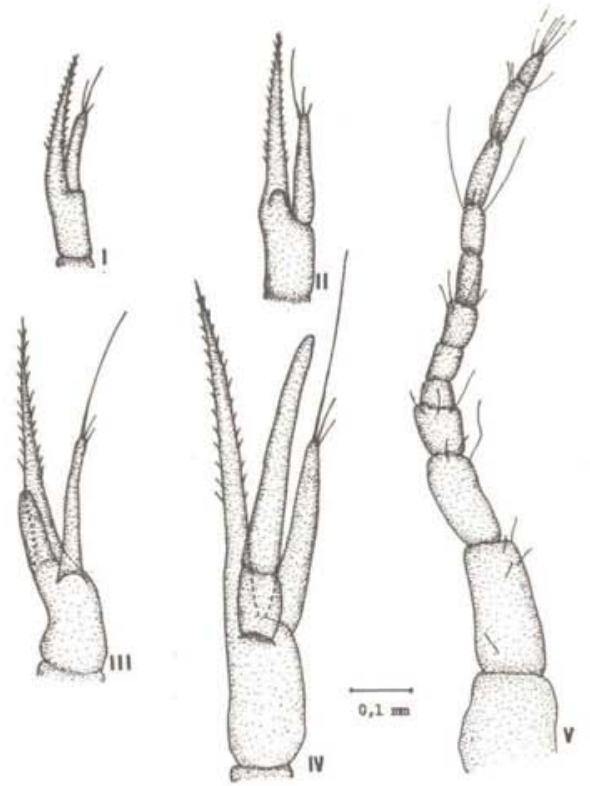

5

Fig. 5: Eriphia gonagra (Fabricius, 1781). Antena, 1, II, III e IV, estágios de zoea e V, megalopa.

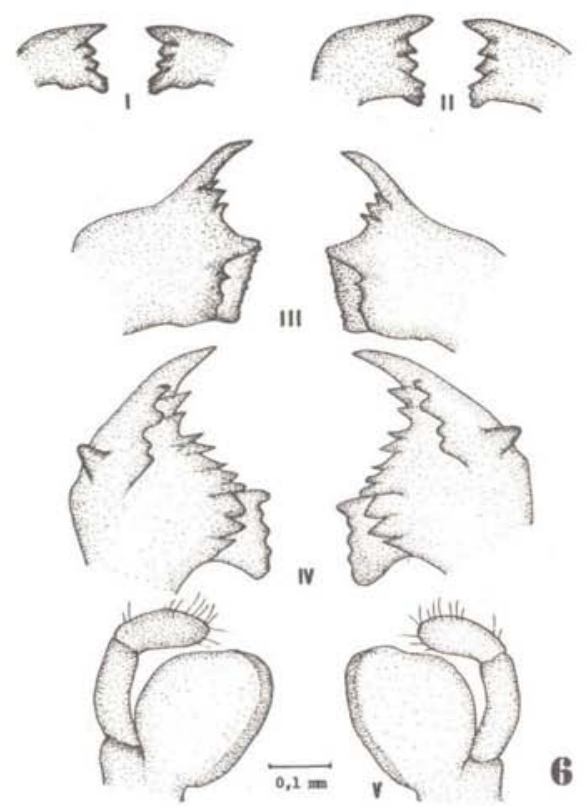

Fig. 6: Eriphia gonagra (Fabricius, 1781). Mandibula, I, II, III e IV, estágios de zoea e V, megalopa. 
Mandibula (Fig. 6-III) - processo incisivo com 4 dentes. Processo molar bem quitinizado com numerosas projeções dentiformes.

Maxilula (Fig. 7-III) - endopodito inalterado. Enditos basal e coxal com respectivamente 11 e 10 cerdas plumosas.

Maxila (Fig. 8-III) - endopodito sem modificações. Endito basal com 5 cerdas plumosas no lobo distal e 6 no proximal. Endito coxal com 4 cerdas plumosas no lobo distal e 7 no proximal. Exopodito com 24 a 26 cerdas plumosas marginais.

Primeiro Maxilipede (Fig. 9-III) - basipodito com o mesmo número de cerdas apresentado pelo estágio anterior. Endopodito com 3, 2, 1, 2 e 6 cerdas plumosas, do segmento proximal para o distal. Exopodito com 8 longas cerdas plumosas no segmento distal.

Segundo Maxilipede (Fig. 10-III) - bastante semelhante ao estágio anterior, mas com o exopodito provido de 8 longas cerdas plumosas distais.

\section{Zoea IV}

(Fig. 1-IV a 10-IV)

A forma do corpo é semelhante à da zoea III. No sexto segmento abdominal surge um par de pleópodos rudimentares, totalizando cinco pares destes apêndices. O terceiro maxilipede e os pereiópodos também aparecem neste estágio, na forma rudimentar.

Telso (Fig. 3-IV) com 12 cerdas plumosas, dispostas 6 a 6 .

Antênula (Fig. 4-IV) - protopodito com 14 estetos e 1 cerda simples. Endopodito bem mais desenvolvido que no estágio anterior e segmentado.

Antena (Fig. 5-IV) - endopodito bisegmentado, desprovido de cerdas e mais longo que o exopodito.

Mandíbula (Fig. 6-IV) - processos incisivo e molar com numerosas projeções dentiformes, em diferentes níveis. Palpo mandibular rudimentar.

Maxilula (Fig. 7-IV) - endopodito não modificado. Endito basal com 14 cerdas plumosas e endito coxal com 9 a 11 .

Maxila (Fig. 8-IV) - endopodito com 3 cerdas plumosas terminais, 2 medianas e 3 proximais. Endito basal com 6 cerdas plumosas em cada lobo. Endito coxal com 5 cerdas plumosas no lobo distal e 10 no proximal. Exopodito com 40 a 43 cerdas plumosas marginais.

Primeiro Maxilipede (Fig. 9-IV) - basipodito e endopodito bem maiores que os do estágio anterior, mas com o mesmo número de cerdas plumosas. Exopodito com 10 longas cerdas plumosas, no segmento distal.

Segundo Maxilipede (Fig. 10-IV) - basipodito mais largo que nos demais estágios. Exopodito com 10 longas cerdas plumosas distais. 


\section{Megalopa}

(Fig. 1-V a 11-V e 12)

A carapaça (Fig. 1-V) é lisa, com uma diminuta projeção rostral, defletida para baixo e pequenas cerdas simples, na região posterior. Olhos grandes e pedunculados. Abdome (Fig. 2-V) ligeiramente mais curto que a carapaça e constituido por 6 segmentos. O segundo, terceiro, quarto e quinto segmentos abdominais são providos de pequenas projeções póstero-laterais. Telso (Fig. 3-V) com margem distal convexa, com 5 pares de pequenas cerdas simples marginais.

Antênula (Fig. 4-V) - com o segmento basal bem desenvolvido, provido de 6 cerdas plumosas. Pedúnculo bisegmentado, com uma fileira de 6 cerdas plumosas no segmento proximal e 3 cerdas lisas no distal. Endopodito (flagelo ventral) segmentado, com 4 cerdas simples distais. Exopodito (Flagelo dorsal) tetrasegmentado, com o segmento proximal liso, o segundo com 10 estetos e 2 cerdas simples, o terceiro com 7 estetos e o distal com 4 estetos e 2 cerdas simples.

Antena (Fig. 5-V) - pedúnculo antenal constituído por 4 segmentos. Segmento basal liso e o segundo, terceiro e quarto apresentam, respectivamente, 5,3 e 3 cerdas simples. Flagelo antenal composto por 8 segmentos com $0,0,4,0,4,2,3$ e 4 (5) cerdas simples, do proximal para o distal.

Mandibula (Fig. 6-V) - provida de uma lâmina cortante, bem quitinizada, com a margem interna lisa. Palpo bisegmentado com 13 cerdas simples no segmento distal.

Maxilula (Fig. 7-V) - endopodito bisegmentado, com 3 cerdas plumosas no segmento proximal e 4 no distal. Endito basal com 20 a 23 cerdas plumosas e endito coxal com 13 a 15 . Protopodito com 1 longa cerda plumosa, na sua margem interna.

Maxila (Fig. 8-V) - endopodito não segmentado, provido de 3 cerdas simples subterminais e 2 cerdas plumosas terminais. Endito basal com 10 cerdas plumosas no lobo distal e 9 no proximal. Endito coxal com 10 cerdas plumosas no lobo distal e 14 (15) no proximal. Exopodito (escafognativo) com 63 a 70 cerdas plumosas maarginais e 4 na superficie subdistal.

Primeiro Maxilipede (Fig. 9-V) - endopodito pequeno, provido de 1 cerda simples proximal e 5 terminais. Endito basal com 28 a 30 cerdas plumosas e endito coxal com 12 a 14. Epipodito bem desenvolvido com 18 cerdas simples. Exopodito bisegmentado, com 4 cerdas plumosas no segmento proximal e 5 no distal.

Segundo Maxilipede (Fig. 10-V) - endopodito tetrasegmentado, com 3, 4, 6 e 7 cerdas plumosas, do segmento proximal para o distal. Epipodito com 15 cerdas simples. Exopodito bisegmentado, com 2 pequenas cerdas plumosas no segmento proximal e 5 maiores no distal. 


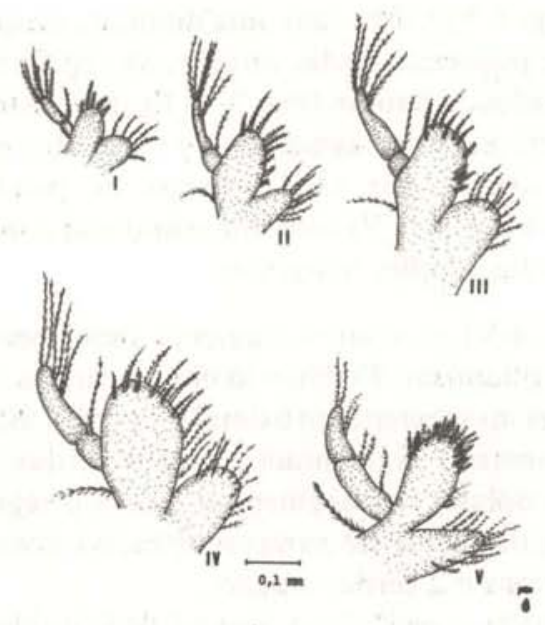

Fig. 7: Eriphia gonagra (Fabricius, 1781). Maxilula, I, II, III e IV, estágios de zoea e V, megalopa.

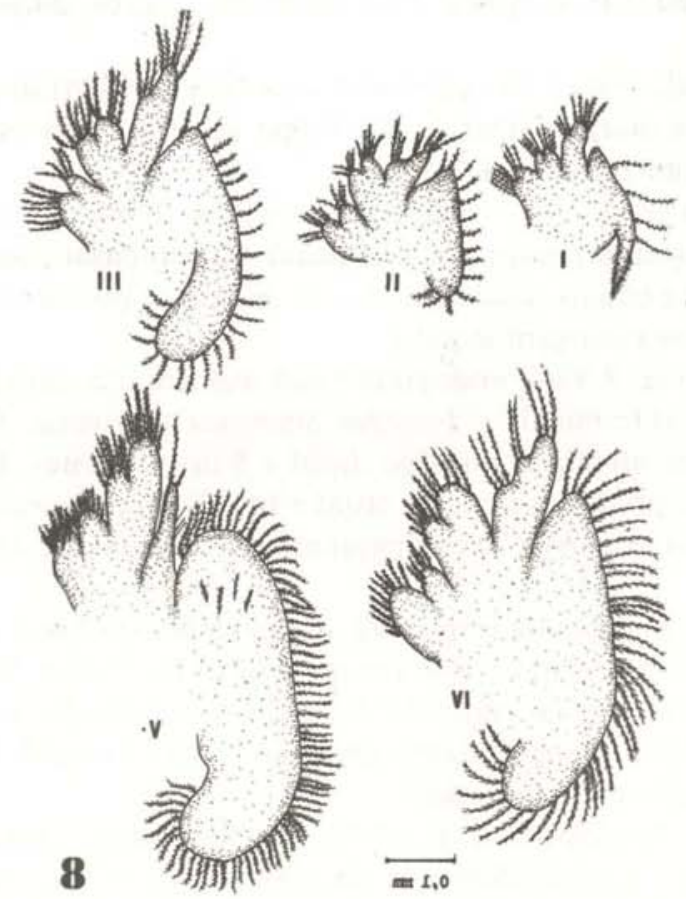

Fig. 8: Eriphia gonagra (Fabricius, 1781). Maxila, I, II, III e IV, estágios de zoea e V, megalopa. 


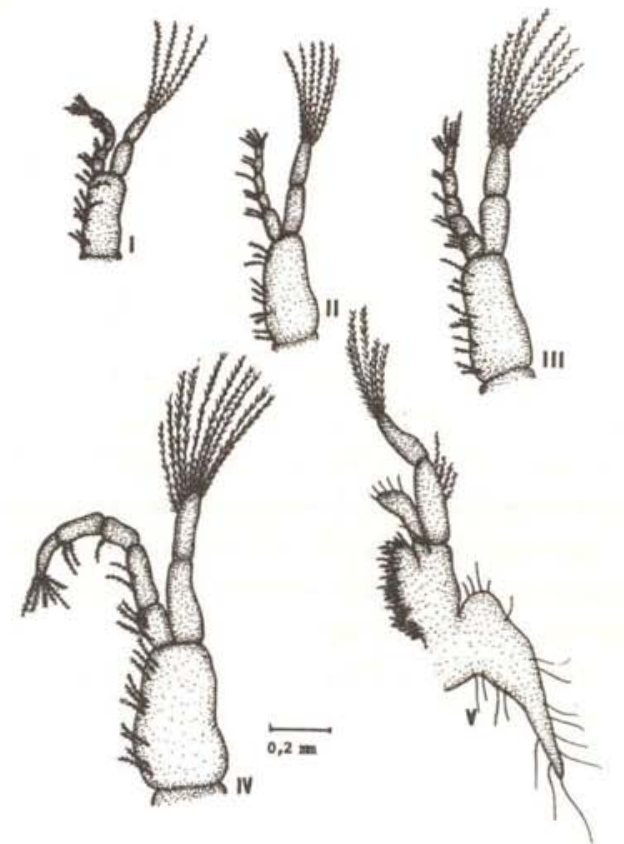

Fig. 9: Eriphia gonagra (Fabricius, 1781). Primeiro maxilipede, I, II, III e IV, estágios de zoea e V, megalopa.

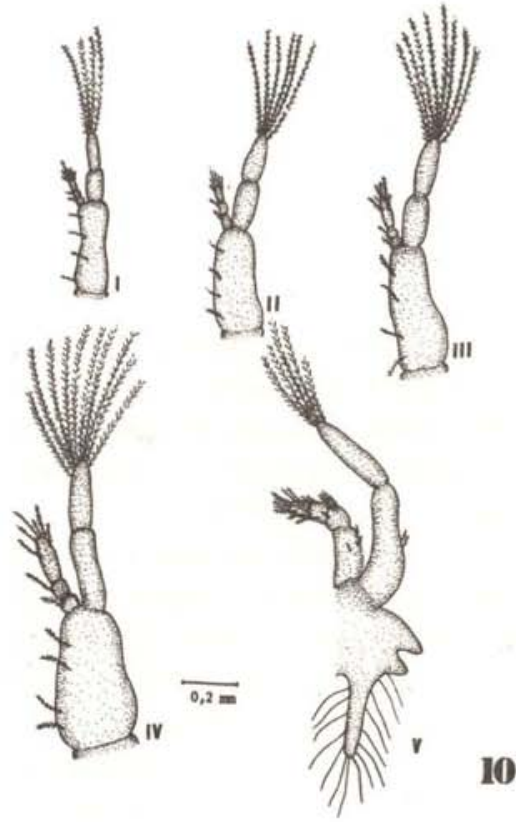

Fig. 10: Eriphia gonagra (Fabricius, 1781). Segundo maxilipede I, II, III e IV, estágios de zoea e V, megalopa. 
Terceiro Maxilipede (Fig. 11-V) - endopodito pentasegmentado, com 18 a 21,20 a $22,13,11$ a 14 e 6 cerdas plumosas do segmento proximal para o distal. Bordo interno do segmento proximal apresentando também alguns pequenos dentes. Epipodito com 9 cerdas plumosas na região basal e 29 longas cerdas simples nas regiões mediana e distal. Exopodito bisegmentado com 5 longas cerdas plumosas terminais, no segmento distal.

Pereiópodos (Fig. 12) - quelipodos (Q) simétricos, com os segmentos providos de pequenas cerdas simples esparsas. O mero apresenta pequenas saliências espinifórmes marginais. O dedo fixo é provido de 4 dentes na margem interna e do dedo móvel de 1 . O segundo, terceiro, quarto e quinto pereiópodos $\left(\mathrm{P}_{2}\right.$ a $\left.\mathrm{P}_{5}\right)$ são bastante semelhantes na estrutura geral e recobertos por cerdas simples esparsas. Quinto pereiópodo com 3 longas cerdas simples no ápice do dáctilo.

Pleópodos (Fig. 11- $\mathrm{P}_{2}$ a $\mathrm{P}_{6}$ ) - em número de cinco pares, localizados ventralmente, do segundo ao sexto somitos abdominais, com uma redução em tamanho do par anterior para o posterior. Exopoditos dos quatro primeiros pares apresentando, respectivamente, 24 (25), 23, 22 (23) e 21 cerdas plumosas. Seus endopoditos possuem respectivamente 6, 5,5 e 4 cerdas unciformes, em posição distal, que se encaixam perfeitamente com as suas simétricas, do mesmo par. O quinto pleópodo é bem menor que os demais, desprovido de endopodito e com 18 cerdas plumosas no expodito.

\section{DISCUSSÃO E CONCLUSÕES}

Entre as espécies da familia Xanthidae com desenvolvimento larval conhecido, aproximadamente $70 \%$ apresentam a fase de zoea constituída por 4 estágios, tal como em E. gonagra. Nas demais espécies ocorre desde desenvolvimento abreviado (ausência de fase de zoea, constatado por Wear, 1967 em Pilumnus novaezealandiae, até 5 ou 6 estágios de zoea, em Menippe mercenaria e Menippe nodifrons, estudadas respectivamente por Porter (1960) e Scotto (1979).

O significado de um maior ou menor número de estágios no desenvolvimento pós-embrionário dos Crustacea tem sido interpretado sob diferentes aspectos. Waterman \& Chace (1960) afirmam que uma importante característica que ocorre, independentemente, no desenvolvimento de muitos grupos de Crustacea é a tendência de estender o período embrionário e encurtar ou eliminar, correspondentemente, as fases larvais. Esta afirmação, sem dúvida, baseia-se no fato de que é altamente vantajoso, para uma determinada espécie, encurtar a fase planctônica, que se caracteriza como um período bastante crítico na vida do animal. $\mathrm{Na}$ opinião de Martin (1984), a razão para um desenvolvimento larval abrevia- 
Vol. 4(3), 1987
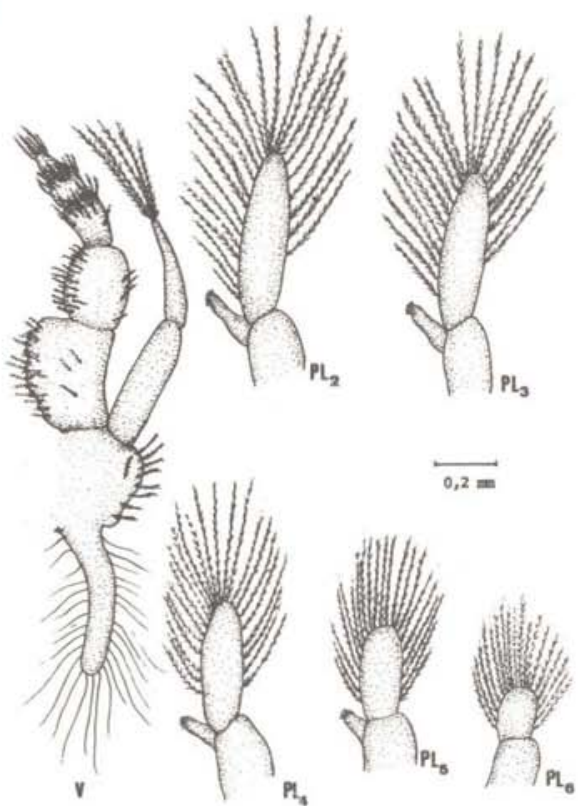

Fig. 11: Eriphia gonagra (Fabricius, 1781). Terceiro maxilipede $\mathrm{V}$, megalopa. $\mathrm{Pl}_{2}-\mathrm{Pl}_{6}$, primeiro ao quinto pleópodos da megalopa.

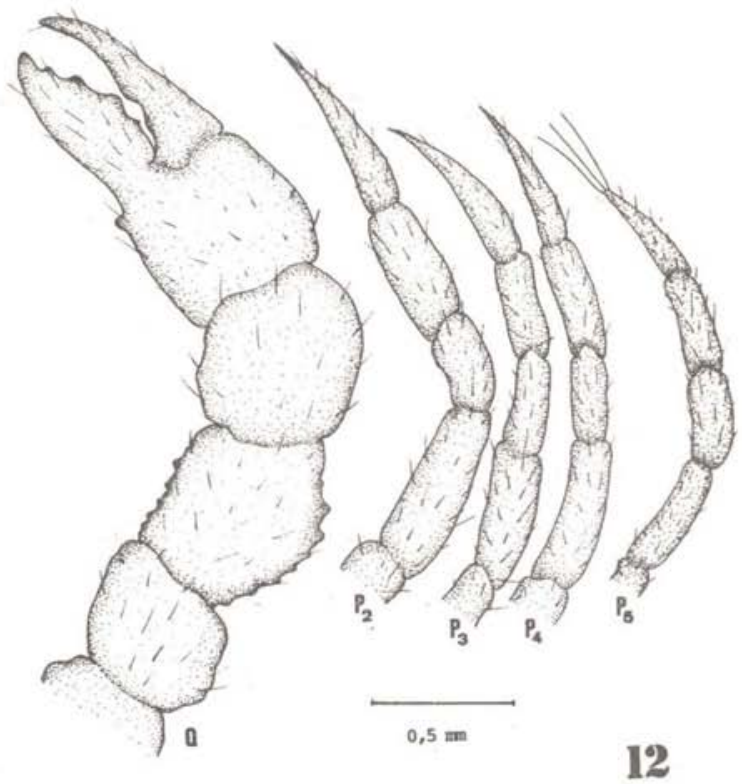

Fig. 12: Eriphia gonagra (Fabricius, 1781). Megalopa. Q, quelipodo; $\mathrm{P}_{2}-\mathrm{P}_{3}$, segundo, terceiro, quarto e quinto pereiópodos. 


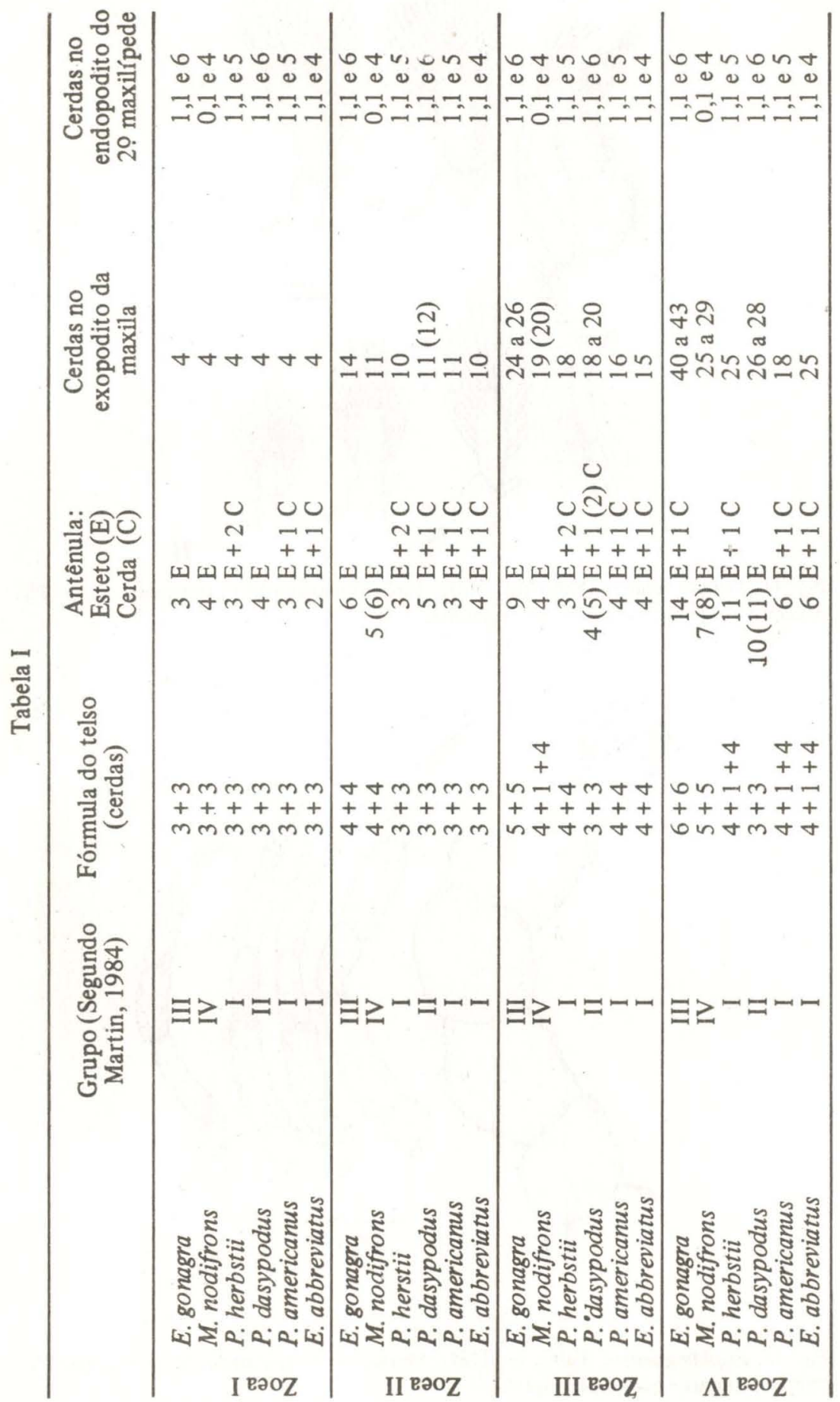


Tabela II

\begin{tabular}{|c|c|c|c|c|c|c|}
\hline & $\begin{array}{c}E . \\
\text { gonagra }\end{array}$ & $\begin{array}{c}M . \\
\text { nodifrons }\end{array}$ & $\begin{array}{c}P . \\
\text { herbstii }\end{array}$ & $\begin{array}{c}P . \\
\text { dasypodus }\end{array}$ & $\begin{array}{c}P . \\
\text { americanus }\end{array}$ & $\begin{array}{c}\text { E. } \\
\text { abbreviatus }\end{array}$ \\
\hline $\begin{array}{l}\text { Número de seg- } \\
\text { mentos da an- } \\
\text { tena }\end{array}$ & 12 & 11 & 9 & 10 & 12 & 11 \\
\hline $\begin{array}{l}\text { Cerdas da E.B. } \\
\text { maxílula E.C. }\end{array}$ & $\begin{array}{l}20 \text { a } 23 \\
13 \text { a } 15\end{array}$ & $\begin{array}{l}28 \text { a } 33 \\
15 \text { a } 19\end{array}$ & $\begin{array}{l}22 \\
14\end{array}$ & $\begin{array}{r}18 \text { a } 20 \\
9 \text { a } 11\end{array}$ & $\begin{array}{l}18 \\
13\end{array}$ & $\begin{array}{l}16 \\
12\end{array}$ \\
\hline $\begin{array}{l}\text { Cerdas margi- } \\
\text { nais no exopo- } \\
\text { dito da maxila }\end{array}$ & 63 a 70 & 66 a 76 & 50 & 34 a 39 & 37 & 38 \\
\hline $\begin{array}{l}\text { Cerdas simples } \\
\text { no epipoditodo } \\
10 \text { maxilípede }\end{array}$ & 18 & 12 a 26 & 7 & 4 a 7 & 7 & 5 \\
\hline $\begin{array}{l}\text { Cerdas simples } \\
\text { no epipoditodo } \\
30 \text { maxilípede }\end{array}$ & 29 & 18 & 23 & 9 & 8 & 12 \\
\hline
\end{tabular}

do ou avançado permanece desconhecida em algumas espécies de Xanthidae, visto que as explicações para o mesmo fato apresentam controvérsias.

Muitos trabalhos, dentre os quais se destacam os de Hyman (1925), Aikawa (1929), Rice (1980) e Gore et al. (1981), foram efetuados com o intuito de subdividir ou reordenar a familia Xanthidae, com base nas enormes variações encontradas nas larvas. Martin (1984) organizou esta familia em seis grupos, sendo que $E$. conagra e $E$. verrucosa enquadramse no terceiro grupo por apresentarem as zoeas com exopodito antenal desenvolvido, com cerca da metade do comprimento do protopodito, sustentando 3 cerdas terminais, segmento distal do endopodito da maxilula com 6 cerdas plumosas terminais das quais 2 são subterminais, endopodito da maxila com 8 cerdas plumosas e segmento basal do endopodito do 2 . maxilipede com 1 cerda plumosa.

Os principais caracteres distintivos entre os estágios larvais de E. gonagra, comparativamente com os das demais espécies de Xanthidae, com ocorrência no Brasil, são apresentados nas tabelas I e II.

Conforme já foi evidenciado por Negreiros-Fransozo (1984), dos 130 gêneros que constituem a familia Xanthidae, apenas 14 são conhecidos com respeito às suas formas larvais, evidenciando uma considerável variação morfológica e indicando a possibilidade de constituirem grupos distintos. 
À Fundação de Amparo à Pesquisa do Estado de São Paulo (FAPESP), pela Concessão das Bolsas de Estudo; ao Departamento de Zoologia do Instituto de Biociências, UNESP, Campus de Rio Claro, onde foi realizado o trabalho; ao Dr. Gustavo A. S. de Mello, do Museu de Zoologia da USP, pela identificação do material.

\section{REFERÊNCIAS}

Aikawa, H., 1929. On larval forms of some Brachyura. Rec. oceanogr. Works Japan 2 (1):17-55.

Birge, E. A., 1883. Notes on the development of Neopanope texana sayi Smith. Stud. Biol. Lab. Johns Hopkins Univ. 2:411-423.

Costlow Jr., J. D. \& C. G. Bookhout, 1961. The larval stages of Panopeus herbstii MilneEdwards reared in the laboratory. J. Elisha Mitchell Sci. Soc. 77:33-42.

Costlow Jr., J. D. \& C. G. Bookhout, 1967. The larval stages of the crab Neopanope packardii (Kingsley), in the laboratory. Bull. Mar. Sci. 17:52-63.

Gore, R. H., C. L. Van Dover \& K. A. Wilson, 1981. Studies on Decapod crustacea from the Indian River region of Florida. XX. Micropanope barbadensis (Rathbun, 1921): The complete larval development under laboratory conditions (Crustacea, Xanthidae). J. Crust. Biol. I(1):28-50.

hyman, O. W., 1925. Studies on the larvae of crabs of family Xanthidae. Proc. U. S. natl. Mus. 67(3):1-22.

Lumare, F. \& S. Gozzo, 1972. Sviluppo larvale del crostaceo Xanthidae Eriphia verrucosa (Forskal, 1775) in condizioni di laboratorio. Boll. Pesca Piscic. Idrobiol. 27(1):185209.

Martin, J. W., 1984. Notes and bibliography on the larvae of Xanthidae crabs, with a key to the known xanthid zoeas of the Western Atlantic and Gulf of Mexico. Bull. mar. Sci. 34(2):220-239.

Negreiros-Fransozo, M. L., 1984. Desenvolvimento pós-embrionário de Pagurus brevidactylus (Stimpson, 1858), Panopeus americanus Saussure, 1857 e Eurypanopeus abbreviatus (Stimpson, 1860) (Crustacea, Decapoda), em laboratório. 133 pp. Tese de doutorado - UNESP - Campus de Rio Claro.

Porter, H. J., 1960. Zoeal stage of the stone crab, Menippe mercenaria Say. Chesapeake Sci. I(3/4):168-177.

Rice, A. L., 1980. Crab zoeal morphology and its bearing on the classification of the Brachyura. Trans. zool. Soc. Lond. 35:271-424.

Sandifer, P. A., 1974. Larval stages of the crab Pilumnus dasypodus Kingsley (Crustacea, Brachyura, Xanthidae) obtained in the laboratory. Bull. mar. Sci. 24(2):378-391.

Scotto, L. E., 1979. Larval development of the Cuban stone crab Menippe nodifrons (Brachyura, Xanthidae), under laboratory conditions with notes on the status of the family Menippidae. Fish. Bull. $77(2): 359-386$.

Waterman, T. H. \& F. A. Chase Jr., 1960. General Crustacean Biology, 1-33. In Waterman, T. H. Ed. The Physiology of Crustacea. Metabolism and Growth. Vol. 1, 699 pp. Academic Press, New York and London.

Wear, R. G. 1967. Life history studies on New Zealand Brachyura. I. Embrionic and postembryonic development of Pilumnus novaezealandiae Filho1, 1886, and of P. lumpinus Bennett, 1964 (Xanthidae, Pilumminae). N. Z. Jl. mar. Freshwat. Res. 1:482535. 